\title{
An Intercomparison of Microphysical Retrieval Algorithms for Upper Tropospheric Ice Clouds
}

Jennifer M. Comstock ${ }^{1}$, Robert d'Entremont ${ }^{2}$, Daniel DeSlover ${ }^{3}$, Gerald G. Mace ${ }^{4}$, Sergey Y. Matrosov ${ }^{5}$, Sally A. McFarlane ${ }^{1}$, Patrick Minnis ${ }^{6}$, David Mitchell ${ }^{7}$,

Kenneth Sassen ${ }^{8}$, Matthew D. Shupe ${ }^{5}$, David D. Turner ${ }^{3}$, and Zhien Wang ${ }^{9}$

${ }^{1}$ Pacific Northwest National Laboratory

${ }^{2}$ Atmospheric and Environmental Research

${ }^{3}$ University of Wisconsin - Madison

${ }^{4}$ University of Utah - Salt Lake City

${ }^{5}$ Cooperative Institute for Research in Environmental Sciences, NOAA/Earth System

Research Laboratory

${ }^{6}$ NASA Langley Research Center

${ }^{7}$ Desert Research Institute

${ }^{8}$ University of Alaska - Fairbanks

${ }^{9}$ University of Wyoming - Laramie

Submitted to the Bulletin of the American Meteorological Society

19 January 2006

Corresponding author address: Dr. Jennifer M. Comstock, Pacific Northwest National Laboratory, PO Box 999 MSIN K9-24, Richland, WA, 99352. Tel: (509) 372-4244, Fax: (509) 372-6168, e-mail: jennifer.comstock@pnl.gov. 


\section{Abstract}

The large horizontal extent, location in the cold upper troposphere, and ice composition make cirrus clouds important modulators of the earth's radiation budget and climate. Cirrus cloud microphysical properties are difficult to measure and model because they are inhomogeneous in nature and their ice crystal size distribution and habit are not well characterized. Accurate retrievals of cloud properties are crucial for improving the representation of cloud scale processes in large-scale models and for accurately predicting the earth's future climate. A number of passive and active remote sensing retrieval algorithms exist for estimating the microphysical properties of upper tropospheric clouds. We believe significant progress has been made in the evolution of these retrieval algorithms in the last decade; however, there is room for improvement. Members of the Atmospheric Radiation Measurement program (ARM) Cloud Properties Working Group are involved in an intercomparison of optical depth $(\tau)$, ice water path, and characteristic particle size in ice clouds retrieved using ground-based instruments. The goals of this intercomparison are to evaluate the accuracy of state-of-the-art algorithms, quantify the uncertainties, and make recommendations for improvement.

Currently, there are significant discrepancies among the algorithms for ice clouds with very small $(\tau<0.3)$ and large $(\tau>1)$ optical depths. The good news is that for thin cirrus $(0.3<\tau<1)$ the algorithms tend to converge. In this first stage of the intercomparison, we present results from a representative case study, compare the retrieved cloud properties with aircraft and satellite measurements, and perform a radiative closure experiment to begin gauging the accuracy of these retrieval algorithms. 


\section{Introduction}

Upper tropospheric ice clouds are important modulators of the earth's climate, cover $20 \%$ of the globe at any given time (Liou 1986), and occur $\sim 43 \%$ of the time in long-term satellite datasets (Wylie and Menzel 1999). Ice clouds, such as cirrus, tend to reflect less incoming solar radiation and absorb more infrared radiation than water clouds, which are typically optically thicker and occur at a lower altitude than ice clouds. Tropical cirrus clouds and convective anvils near the Tropical Tropopause Layer (TTL) may play an important role in stratospheric-tropospheric water vapor exchange and dehydration of air in the TTL (Rosenfield et al. 1998; Sherwood 1999; Hartmann et al. 2001; Holton and Gettelman 2001; Jensen and Pfister 2004). Accurate cloud property retrievals are important for understanding the radiative feedback of high clouds, and parameterization development for global models.

One of the key uncertainties in climate model simulations is the feedback of upper tropospheric clouds on the earth's radiation budget. The goals of the Global Energy and Water Cycle Experiment (GEWEX) Cloud System Study (GCSS) involve bringing together members of the observational and modeling community to "facilitate the development and testing of improved cloud parameterizations for climate and numerical weather prediction models" (Randall et al. 2003). In particular, the GCSS Working Group 2 (WG2; http://eos913c.gsfc.nasa.gov/gcss_wg2/) focuses on cirrus clouds. Some of the goals of WG2 include determining the level of microphysical complexity required for adequate treatment of cirrus clouds in large-scale models and what degree of complexity is required for the treatment of ice clouds in remote sensing applications. 
Clearly there is a need by the modeling community to understand the uncertainty and validity of the measurements that are being used to develop cloud parameterizations.

Radiative forcing is used extensively in the Intergovernmental Panel on Climate Change Third Assessment Report (IPCC 2001) to determine our level of understanding concerning the effects of aerosols, clouds, and greenhouse gases on the earth's radiation budget. A key factor in understanding the impact of clouds on the radiation budget is determining the cloud radiative forcing (CRF). To calculate the CRF, it is essential to have accurate estimates of both clear and cloudy sky fluxes at the surface. Clear sky shortwave fluxes can be computed to within $10 \mathrm{~W} \mathrm{~m}^{-2}$ of measured fluxes if the appropriate inputs (i.e. aerosol properties, surface albedo, water vapor etc.) are used in the model (Ackerman et al. 2003; Michalsky et al 2005). Model clear sky longwave fluxes agree with measurements to within $\pm 2 \mathrm{~W} \mathrm{~m}^{-2}$ if proper representation of the water vapor continuum is included in the model (Marty et al. 2003; Turner et al. 2004). Modeling cloudy sky fluxes is a more difficult problem because it requires knowledge about the cloud optical thickness and scattering properties of the hydrometeors that constitute the cloud, as well as the fractional sky cover and the extent of cloud inhomogeneity. For ice clouds, there is the added uncertainty concerning the ice crystal habit (i.e., the morphology of the ice crystals), which strongly affects both the scattering of solar energy and the absorption of infrared energy. The radiative properties (i.e. optical depth, phase function, and single scatter albedo) and the microphysical properties (i.e. hydrometeor size; ice crystal shape, and ice / water content) are critical for estimating the cloud radiative forcing, which is an important tool 
for understanding the effect of clouds on the radiation budget and assessing the representation of clouds in climate models.

For over 10 years, the Department of Energy's (DOE) Atmospheric Radiation Measurement (ARM) program has monitored the atmospheric state with its primary foci on understanding the interaction of clouds and radiation and using this knowledge to improve the parameterization of clouds in GCMs (Ackerman and Stokes, 2003). The goal of the ARM Cloud Properties Working Group (CPWG) is to develop and implement algorithms that characterize the physical state of the cloudy atmosphere, including cloud occurrence, cloud condensed water amount, and cloud optical properties for all sky conditions. For example, members of the CPWG have developed a complex algorithm for detecting cloud boundaries using a combination of radar, lidar, and ceilometer measurements (Clothiaux et al. 1998). A similar project called Microbase is currently underway to develop a continuous baseline cloud microphysical properties product for water, ice, and mixed phase clouds using ARM measurements. Currently, a subgroup of the CPWG is focusing on the retrieval of microphysical properties from ice clouds. This group is actively comparing various remote sensing retrieval algorithms. These algorithms use some combination of radar, lidar, and/or infrared (IR) radiance measurements and are divided into several different classes. Eventually, the CPWG will recommend a suite of algorithms for implementation into microbase. It is important that the recommended algorithms be able to span the entire dynamic range of ice clouds expected at a given site, and thus climatologies are being used to provide guidance on the expected range of the microphysical properties (e.g., Sassen and Comstock 2001 for the ARM Southern Great Plains site in Oklahoma). 
Our goals in this overview are:

- To introduce the basic principles of each class of retrieval algorithm (see Table 1 for a summary of algorithms).

- Present a case study examining the ability of these state-of-the-art retrievals to retrieve cloud properties.

- To discuss the challenges and possible avenues for evaluating the skill with which these algorithms can retrieve cloud properties.

\section{The Retrieval Algorithms}

There are a wide variety of different retrieval algorithms that are used to retrieve cirrus microphysical properties. These algorithms differ in their complexity, the instrument data used, and in their assumptions; however, they can generally be separated into distinct classes.

\subsection{Regression relationships}

Empirical regression relationships are the simplest retrievals and have been developed based on a combination of in situ and ground based measurements. These regressions generally have the form $I W C=a Z^{b}$, where IWC is the ice water content, $Z$ is the observed radar reflectivity (typically from a cloud radar with a 3 or $8 \mathrm{~mm}$ wavelength), and $a$ and $b$ are regression coefficients that are commonly available in the literature (Liao and Sassen 1994; Atlas et al. 1995; Liu and Illingworth 2000; Matrosov et al. 2003). The primary benefit of using regression techniques is their simplicity. However, the weakness of this technique is that these relationships have a strong temperature and particle size dependence (Atlas et al. 1995; Liu and Illingworth 2000) 
that cause differences in the derived $a$ and $b$ coefficients, which increases the uncertainty in the retrieved IWC.

\subsection{Spectral infrared algorithms}

Passive IR and visible measurements have been widely used to retrieve cloud properties from satellite (i.e. King et al. 1992; Wielicki et al. 1996; Minnis et al. 1998) and ground based instruments (i.e. Min and Harrison 1996; Barnard and Long 2004; Marshak et al. 2004). In recent years, algorithms have been developed that utilize high spectral resolution measurements in the infrared spectrum by the Atmospheric Emitted Radiance Interferometer (AERI) to retrieve cloud properties at the surface (DeSlover et al. 1999; Mitchell et al. 2002; Turner 2005). The infrared spectrum is relatively transparent to gaseous absorption and emission; however absorption/emission by water vapor contributes significantly to the measured infrared signal at the surface. The advantage of using high spectral resolution measurements is that we can utilize "microwindows" that lie between absorption lines in the IR spectrum. This minimizes the contribution of water vapor and other gases to the measured radiance. Nonetheless, it is crucial to incorporate an accurate radiative transfer model (such as the Line-by-Line Radiative Transfer Model; Clough and lacono 1995), as well as an accurate water vapor continuum absorption model, and temperature and humidity profiles, into spectral IR algorithms. Infrared retrieval algorithms are limited as the IR optical depth approaches 6-8 due to saturation in the IR signal.

\subsection{Lidar/Radar and infrared radiometer algorithms}

As the use of active remote sensors in cloud studies matured in the 1970's-1990's researchers began to focus on the development of combined remote sensor 
microphysical retrievals. One of the original algorithms combined a $694 \mathrm{~nm}$ lidar with 10-12 $\mu \mathrm{m}$ radiometric observations to retrieve layer visible optical depth $\left(\tau_{v}\right)$ and IR emittance $(\varepsilon)$ in small optical depth clouds and is commonly referred to as the LIRAD method (Platt 1973; Platt and Dilley 1981; Comstock and Sassen 2001). The LIRAD method relates the integrated backscatter coefficient measured by the lidar to the IR absorption optical depth $\left(\tau_{\mathrm{a}}\right)$, allowing $\tau_{\mathrm{a}}$ to be retrieved through an iterative procedure. In addition to the LIRAD method, IR radiance measurements have also been combined with radar reflectivity measurements (i.e. 35 and $94 \mathrm{GHz}$ frequency radar) to retrieve layer integrated microphysical properties such as particle size and IWC (Matrosov et al. 1992; Mace et al. 1998). In recent years, the reflectivity-IR (ZIR hereafter) technique has been expanded to retrieve vertical profiles of IWC and particle size, exploiting the profiling capabilities of the active remote sensors (Matrosov 1999).

As with the spectral infrared methods, these combined techniques require that the water vapor absorption be removed from the measured IR radiance, and therefore exhibit the same upper limit in retrieved optical depth due to saturation. In addition to this limitation, algorithms that utilize lidar are restricted to $\tau_{v}<3$ due to the attenuation limiting nature of visible wavelength lidar in dense clouds.

\subsection{Lidar-radar algorithms}

Lidar-radar (LR) algorithms combine lidar backscatter or extinction coefficient profiles with cloud radar reflectivity profiles to retrieve particle size, IWC, and optical depth (Intrieri et al. 1993; Donovan and van Lammeren 2001; Wang and Sassen 2002). The advantages of lidar-radar algorithms are two-fold. First, since lidars and radars operate at different wavelengths they are sensitive to different size scatterers. For 
example, scattering at microwave radar wavelengths is dominated by larger particles. Radars typically do not detect small particles unless large concentrations are present. Radars are therefore unable to detect optically thin cloud layers and the uppermost portion of cirrus clouds where ice nucleation produces small ice crystals. Lidar wavelengths (typically ultraviolet, visible, and infrared wavelengths are used in cloud remote sensing) are sensitive to the small particles. However, attenuation of the lidar beam limits the detection of cloud top when optically thick clouds are present. The differences in the sensitivity of lidar and radar to different size particles can be used to our advantage to retrieve particles sizes (i.e. Donovan and van Lammeren 2001). The second advantage of lidar-radar algorithms is they provide high vertical and temporal resolution profiles of cloud microphysical properties, which makes it possible to compute radiative heating/cooling rates in the atmosphere (this is true for any algorithm that provides vertical profiles of cloud microphysical properties). One disadvantage of LR algorithms is that they are typically applied only in regions where both the lidar and radar detect cloud.

\subsection{Radar reflectivity-Doppler velocity algorithms}

Radar reflectivity-Doppler velocity (ZV) algorithms rely solely on Doppler radar measurements to retrieve vertical profiles of IWC and particle size (e.g. Matrosov et al. 2002; Mace et al. 2002). The advantage of this technique is that the algorithm is not limited by either lidar attenuation or IR saturation. This makes ZV algorithms advantageous for retrieving cloud properties in multi-layered cloud scenes (i.e. cirrus above low level stratus) and optically thick clouds $\left(\tau_{v}>5\right)$. The $Z V$ algorithm relies on empirical relationships that relate the fall velocity $\left(v_{t}\right)$ of ice crystals with the particle size 
(D) (e.g., $\left.v_{t}=A D^{B}\right)$, which are typically derived from aircraft in situ particle size

distribution measurements or model simulations. However, prior to applying this type of retrieval, the contribution of the ice crystal fall speed to the measured mean Doppler velocity must be distinguished from large scale mesoscale motions and cloud turbulence motions. As with the LR algorithms, ZV algorithms are also limited by the ability of the radar to detect clouds that are below the sensitivity level of the radar.

\subsection{Case study comparison}

Ideally, a case study to intercompare ice cloud retrieval algorithms would involve a single layer, horizontally homogeneous cloud with complete overcast skies. Given the inherent inhomogeneity of cirrus clouds, the ideal case does not exist. However, we are able to isolate single layer cases with relatively uniform cloud thickness. Since the algorithms included in this study all involve vertically pointing, narrow field-of-view (FOV) instruments, differences in retrieved cloud properties are not generally caused by the three-dimensional (3D) nature of the clouds, but rather by the instrument capabilities and retrieval assumptions. For example, we do not include retrievals that use hemispheric instruments, which may rely on diffuse measurements of the radiative field to retrieve cloud properties.

Based on the above criteria, we have chosen a case observed on 9 March 2000 at the ARM Southern Great Plains (SGP) Climate Research Facility to illustrate the differences in each algorithm class. This case occurred during the 2000 Cloud Intensive Observing Period (IOP) sponsored by the DOE ARM program, and therefore includes accompanying measurements that are not normally available at the ARM sites, such as 
aircraft in situ and scanning radar measurements (Mace et al. 2006). We will use some of these auxiliary measurements in our discussion of retrieval validation.

The cirrus cloud observed on 9 March 2000 formed as a weak upper level disturbance propagated over the SGP region in a strong southwesterly flow. The initial cloud formation occurred as the weak disturbance passed over the mountains of central New Mexico during the local morning of 9 March. The clouds thickened into a series of bands oriented along the wind as the disturbance moved northeastward. Whole sky imagery (Fig. 1) reveals that the optically thin cirrus drifting overhead is very inhomogeneous with a cloud fraction much less than 1 for most of the time. During the 2000 Cloud IOP, the University of North Dakota (UND) Citation aircraft flew numerous flight patterns in cirrus with overpasses of the SGP site. Flight patterns include "figure eights", and Eulerian and Lagrangian spirals. The Citation housed a Cloud Particle Imager (CPI, Lawson et al. 2001), which reveals that the predominant particle shape for this cirrus is bullet rosettes (Fig. 1, Heymsfield et al. 2002).

\subsection{Retrieval Intercomparison}

Vertically pointing millimeter cloud radar (MMCR) and Micropulse Lidar (MPL) measurements illustrate the evolution of the cirrus cloud as it passes over the ARM SGP (Fig. 2). The visible optical depth varied by 2-3 orders of magnitude over the 3.5 hour time period, which is typical for midlatitude synoptically generated cirrus clouds that are initially optically thin $\left(\tau_{v}<0.3\right)$ and tend to increase in optical thickness as the cloud system passes overhead. While this range in $\tau_{v}$ is large, it allows us to understand the strengths and limitations of each retrieval type. The results from several algorithms converge or diverge depending on the optical depth range. 
The time-height images of radar reflectivity and lidar backscatter demonstrate the strengths and weaknesses of these two instruments. For example, the optically thin cloud detected by the MPL between 9 and $10 \mathrm{~km}$ from 2200-2230 UTC is only partially detected by the MMCR. On the other hand, it is evident that the MPL is often attenuation limited (i.e. 2100-2130) and reports a much lower cloud top height than the MMCR. This discrepancy in cloud heights measured by radar and lidar has been demonstrated previously (i.e. Intrieri et al. 1995; Comstock et al. 2002), but is emphasized here in the context of retrieval algorithms.

\section{Optically Thin Clouds $(\tau<0.3)$}

For optically thin clouds $(1900-1915 ; 2200-2230$ UTC), it is clear that the retrievals diverge by 1-2 orders of magnitude in $\tau$ and up to a factor of 20 in IWP (Figs. 3 and 4). The ZV algorithms tend to retrieve much smaller $\tau$ and IWP than algorithms that include both radar and lidar (LR), or use lidar only (Raman and COM-Lidar). The AERI and ZIR algorithms coincide with the lidar-only $\tau_{v}$ relatively well, although the AERI-only algorithms appear to have a minimum detectability of $\tau_{v} \sim 0.1$. Similar trends are seen in the IWP retrievals; however the AERI only algorithms demonstrate increased scatter in IWP as compared with the $\tau_{\vee}$ retrievals.

\section{Optically Thicker Clouds $\left(\tau_{v}>0.3\right)$}

When referring to mid and upper tropospheric ice clouds, the term "optically thick" refers to those clouds that have a $\tau_{v}$ between $\sim 0.3$ and 10.0. As compared with clouds such as deep convection, these clouds are not considered optically thick. However, since the range of $\tau_{v}$ observed in cirrus and altostratus clouds varies by 4 orders of magnitude, we will use this terminology to distinguish thin and thick ice clouds. The 
majority of the cloud observed during the 9 March 2000 case falls into this "optically thick" category.

As with the optically thin clouds, the retrievals exhibit a large spread in both IWP and $\tau_{v}$ (Figs. 3 and 4). Upon closer inspection, some trends are seen. The algorithms that use the lidar (lidar only, LR) and those that use IR measurements (ZIR and AERI) tend to have similar optical depths during the $2100-2145$ time period. Although these algorithms appear to be in good agreement, inspection of the lidar and radar images indicate that during this time period, the lidar is attenuation limited in the optically thickest portion of the cloud. Therefore, the lidar-based algorithms are biased low because of lidar attenuation. Note that the two ZV algorithms have a large spread in $\tau_{\vee}$ during this time period as well. This emphasizes that although the retrieval techniques are fundamentally the similar, the retrieval assumptions introduce uncertainty in the retrievals. During this same time period, the wide range in IWP for all retrievals also emphasizes the increased uncertainty during periods when the cloud depth is largest.

For $\tau_{v}$ and IWP in the 2000-2100 UTC time period, all retrieval algorithms tend to converge more closely. This makes sense, since the limitations for each technique (i.e. IR saturation, inability to detect cloud etc.) is not an issue for this optical depth range $\left(\tau_{v} \sim 0.3-1.0\right)$

\subsection{The Challenges of Retrieval Validation}

Since one of the goals of this intercomparison project is to recommend an algorithm or suite of algorithms to the ARM program for operational retrievals of ice cloud microphysical properties, it is important to discuss methods for verifying the results. There are a number of challenges when attempting to evaluate retrieval algorithm 
performance. Ideally, the radiance/flux closure exercise should not use the same instrument or wavelength that is used in the retrievals. Here, we explore comparisons with auxiliary, independent measurements, as well as radiative closure experiments to evaluate retrieval performance.

\subsection{Comparisons with Independent Observations}

On 9 March 2000, the UND Citation aircraft also housed a counterflow virtual impactor (CVl; Twohy et al. 1997). We compare IWP derived from the CVI with the range of IWP retrieved using the ground-based remote sensors (Fig. 5). The mean CVI IWP is generally larger than the ground-based retrieved IWP; however the standard deviation (vertical bars) overlap with the min/max envelop of the retrieved quantities.

Some of the challenges that arise when comparing in situ measurements with groundbased retrievals include size of the sample volume, particle breakup, and instrument sensitivities or limitations. For example, the CVI collects cloud particles at a rate of $\sim 0.15 \mathrm{~m}^{3} \mathrm{~min}^{-1}$, whereas the SGP MMCR and MPL have sample volumes on the order of $\sim 10^{4} \mathrm{~m}^{3}$ and $\sim 10^{3} \mathrm{~m}^{3}$, respectively at $\sim 10 \mathrm{~km}$ above ground level. Additionally, the uncertainty in collocating the in situ observations in time and space with the remote sensing retrievals is considerable. Despite this large discrepancy in sample volume, the agreement between the CVI probe and the ground-based retrievals is usually within a factor of two.

In addition to in situ measurements, we can also compare with geostationary satellite (GOES) observations. In Fig. 5, we compare the ground-based retrievals of IWP and $\tau$ with the Visible Infrared Solar Split Window Technique (VISST), which uses solar reflectance and IR brightness temperature to retrieve cloud properties for each pixel 
(Minnis et al., 1995, 1998, 2004). The VISST retrievals of IWP are in general agreement with the ground-based observations during the thicker cloud regions, but tend to overestimate the IWP when the clouds are optically thin. This result is similar for the optical depth results. As with the in situ probes, there is a large discrepancy between the pixel area of the GOES observation and the area of the remote sensor. In this case, the VISST retrieval is for a $0.5 \times 0.5^{\circ}$ area (or $\sim 2300 \mathrm{~km}^{2}$ footprint) vs. the MMCR and MPL footprints of $\sim 850 \mathrm{~m}^{2}$ and $\sim 450 \mathrm{~m}^{2}$ at $10 \mathrm{~km}$, respectively. Sample volume and area are one of the primary challenges when comparing measurements from different platforms. This especially important when the clouds are inhomogeneous and broken.

\subsection{Radiative Closure Experiments}

Radiative closure is one tool used to evaluate retrieved microphysical properties. The basic idea is to insert the retrieved microphysical properties into a detailed radiative transfer algorithm, compute either the hemispheric fluxes or radiances, and compare these model values with observations. Comparisons can be made at either the surface or top-of-atmosphere (TOA). Typically, surface fluxes are compared with shortwave pyranometers and TOA fluxes are compared with outgoing longwave radiation measured by satellite sensors.

Flux and radiance calculations depend on the optical depth of the layer and the scattering or optical properties of the hydrometeors in that layer (i.e. phase function and single-scattering albedo). Therefore, if the algorithm retrieves optical depth and particle size, you can choose the single-scattering properties based on a parameterization (i.e. Fu and Liou 1993; Ebert and Curry 1992), which generally assume a single particle shape. Another approach is to develop a database of single-scattering properties based 
on particle size and shape. In either case, the particle shape is unknown (unless in situ measurements of particle habit are available) and must be assumed, introducing uncertainty in the radiative closure experiments.

\subsubsection{Flux Closure}

As an example of radiative flux closure at the surface, we examine the 9 March case study (Fig. 6) to demonstrate how well the retrieved microphysical properties predict the surface shortwave flux. For this demonstration, we use the minimum, maximum, and average optical depth as input to the radiative transfer code. During the $2100-2200$ UTC time period, the range in optical depth encompasses the observed downwelling flux from the shortwave pyranometer located at the ARM SGP site, with larger optical depths providing the closest agreement. As mentioned previously, this time period corresponds with the optically thickest portion of the cloud, which would have the most horizontally homogeneous, overcast appearance. Optically thin cirrus clouds have a fibrous appearance with large amounts of blue sky visible through the cloud layer, while optically thicker clouds will have a more overcast appearance (see Fig. 1). Time periods when the cloud is more overcast (i.e. larger cloud fraction) will not be as affected by 3D radiative effects. The thinner cloud sections (i.e. 1830-1900 UTC) will have much smaller cloud fractions, but are subject to 3D effects, which could explain the poor agreement during these time periods.

\subsubsection{Radiance Closure}

To demonstrate radiance closure, we compare model radiances with observations of downwelling radiance in the 3.8314-3.846 $\mu \mathrm{m}$ microwindow measured by the AERI. This midwave-IR microwindow excludes absorption lines but is strongly influenced by 
scattering during the daytime. This approach tests how well the retrieved microphysical properties accurately represent both scattering and absorption in the layer. An advantage of this approach is that we are using the AERI, which is a narrow field-ofview (FOV) instrument that measures a "pencil beam" of radiance rather than the hemispherical FOV of the flux radiometers. This reduces the contributions of $3 \mathrm{D}$ effects and better complements the narrow FOV of the active and passive remote sensors used in the retrievals.

For each retrieval algorithm in Table 1, we directly compare the measured and model radiances (Fig. 7). We have divided the results into two groups; algorithms that do not utilize IR measurements (Fig. 7a) and those that do (Fig. 7b). The majority of the algorithms are biased low as compared with observations. The algorithms that include IR measurements appear to be better constrained but almost always biased low. The non-IR-based algorithms (LR, EMP, and ZV) exhibit more scatter than the IR algorithms, and are generally biased low, except for two algorithms that are often biased significantly higher than the observed radiance. The discrepancy between model and measured radiances differs on average by $-14 \pm 64 \%$ If we average the radiance differences from all of the algorithms according to optical depth ranges, the averages are $-33 \pm 34 \%,-14 \pm 62 \%$, and $-2 \pm 77 \%$ for $\tau_{v}<0.3,0.3<\tau_{v}<1.0$, and $\tau_{v}>1.0$, respectively.

\subsection{Further Challenges}

\section{Assumptions of Ice Crystal Shape and Particle Size Distribution}

Clouds containing ice crystals pose an added difficulty to cloud properties retrieval. There are currently only limited techniques for determining the particle shape in ice clouds; however, some recent research has shown promising results using polarization- 
sensitive instruments (Matrosov et al. 2001, Noel et al. 2002). Each retrieval approach must make some assumption concerning ice crystal shape, which can make a significant impact on the retrieved microphysical properties, particularly for particle size (not shown) and IWP (see Fig. 3 and 4).

In addition, most algorithms must make some assumption concerning the shape of the particle size distribution (PSD; i.e. lognormal, gamma, bimodal etc) and most assume a single mode function. There is evidence that the bimodal size distribution may be common in many ice clouds, including mid-latitude frontal (Korolev and Isaac 2005) and cirrus (Heymsfield and Platt 1984; Arnott et al. 1994), and tropical anvil cirrus (McFarquhar and Heymsfield 1996). Since PSDs are exclusively measured by aircraft in situ probes, there exists some controversy concerning the contribution of small particles to the total size distribution. The controversy primarily encompasses the ability of in situ probes to accurately measure particle sizes given the small sample volumes of the probes, and the possibility of large particle breakup on probe inlets. This is currently an active area of research and a source of debate in the community.

Since each algorithm makes some assumption concerning the PSD and ice crystal shape, discrepancy among algorithms maybe reduced if these assumptions were treated consistently between algorithms.

\section{Uncertainty Estimates}

In this overview, we have presented the retrieved microphysical and radiative properties from several fundamentally different approaches. We have not discussed the uncertainty associated with each algorithm or the challenge in estimating uncertainty for any given algorithm. In recent years, the community has become increasingly aware of 
the importance of developing uncertainty estimates on measured or retrieved cloud properties because the applications of these properties include comparisons with model simulations, model parameterization development, and for understanding cloud processes from the cloud scale to the large scale. Recently, estimation theory (Jawinsky 1970; Rodgers 2000), such as the general Bayesian approach (i.e. McFarlane et al. 2002) or the more specific optimal estimation approach (i.e. Austin and Stephens 2001, Stephens et al. 2001; Benedetti et al. 2003; Mitrescu et al. 2005), have been applied to inverse retrieval problems related to the atmospheric sciences. The advantage of using estimation theory to tackle inverse problems is that it supplies a method for propagating errors and uncertainties in the measurements and assumptions in the retrieval algorithm. This supplies a more comprehensive and mathematically consistent approach to error propagation. Two of the algorithms presented in this overview have applied estimation theory to their retrievals (Mace et al. 1998; Turner 2005). Regardless of the method chosen, it is clear that a consistent approach to error analysis is needed when combining multiple techniques for retrieval of cloud properties from all clouds (i.e. water, mixed phase, ice) on a continuous basis, as is the goal of the ARM program.

\section{Path Forward}

One case is not enough to thoroughly understand our ability to retrieve ice cloud microphysical properties. The case study presented here is one of several cases examined as part of this intercomparison. Similar trends in the closure experiments were observed in those cases as well. Given the vast data archive available through the ARM program, comparisons of this kind can be extended to include different seasons, different cloud types (i.e. anvil cirrus, wave clouds, synoptic generated cirrus, etc.), and 
different dynamical regimes. This will enable us to develop statistics on how these retrievals perform under various conditions.

Although these comparisons will hopefully lead us to understand how well we can retrieve cloud properties, the real question lies in how can we use this knowledge to improve the retrieval algorithms themselves. There are several open questions concerning ice cloud retrievals that face us today. One is the contribution of small particles to the particle size distribution. If small particles are as prevalent as in situ data suggest, our approach to remote sensing may be impacted. For example, since the radar reflectivity is weighted toward larger particles, do radar approaches bias the retrieval of particle size and IWP? On the other hand, the IR and lidar approaches are sensitive to other portions of the particle size distribution, which could also introduce biases. Given the broad particle size distributions that may exist in cirrus clouds, a serious look at multi-sensor, multi-wavelength approaches may assist the improvement of cloud property retrievals.

Another way to understand the strengths and weaknesses of a retrieval algorithm is to apply the retrieval to simulated remote sensing data, where a cloud microphysical model rovides the atmospheric state and cloud microphysical properties (e.g., Sassen et al 2002). However, any inadequacies in the forward model used to simulate the remote sensor's observations, such as consistency of the single scattering properties with wavelength, cannot be addressed with a study such as this.

We have not attempted in this paper to answer the question of which algorithm is best. But rather have summarized the challenges that arise in understanding how these 
state-of-the-art algorithms perform, and where the focus should be directed in the future.

Acknowledgements. This research was supported by the Office of Biological and Environmental Research of the U.S. Department of Energy as part of the Atmospheric Radiation Measurement Program. We thank David Donovan and Gerd-Jan van Zadelhoff for providing their lidar-radar retrieval code.

\section{References}

Ackerman, T. P., and G. M. Stokes, 2003: The Atmospheric Radiation Measurement program, Physics Today, 56, No. 1, 38-44.

Ackerman, T. P., D. M. Flynn, and R. T. Marchand, 2003: Quantifying the magnitude of anomalous solar absorption. J. Geophys. Res., 108, 10.1029/2002JD002674.

Arnott, W. P., Y.-Y. Dong, and J. Hallett, 1994: Role of small ice crystals in radiative properties of cirrus: a case study, FIRE II, November 22, 1991. J. Geophys. Res., 99, 1371-1381.

Atlas, D., S. Y. Matrosov, A. J. Heymsfield, M. D. Chou, and D. B. Wolff, 1995: Radar and radiation properties of ice clouds, J. Appl. Met., 34, 2329-2345.

Austin, R. T., and G. L. Stephens, 2001: Retrieval of stratus cloud microphysical parameters using millimeter-wave radar and visible optical depth in preparation for CloudSat 1. Algorithm formulation. J. Geophys. Res., 106, 28233-28242.

Benedetti, A., G. L. Stephens, and J. M. Haynes, 2003: Ice cloud microphysics retrievals from millimeter radar and visible optical depth using an estimation theory approach. J. Geophys. Res., 108, 10.1029/2002JD002693. 
Barnard, J. C., and C. N. Long, (2004): A Simple Empirical Equation to Calculate Cloud Optical Thickness Using Shortwave Broadband Measurements, J. Appl. Meteor., 43, 1057-1066.

Clothiaux, E. E., G. G. Mace, T. P. Ackerman, T. J. Kane, J. D. Spinhirne, and V. S. Scott, 1998: An automated algorithm for detection of hydrometeor returns in micropulse lidar data. J. Atmos. Oceanic Tech., 15, 1035-1042.

Clough, S. A., and lacono, M. J., 1995: Line-by-line calculation of atmospheric fluxes and cooling rates, 2. Application to carbon-dioxide, ozone, methane, nitrous-oxide, and the halocarbons, J. Geophys. Res., 100, 16519-16535.

Comstock, J. M. and K. Sassen, 2001: Retrieval of cirrus cloud radiative and backscattering properties using combined lidar and infrared radiometer (LIRAD) measurements. J. Atmos. Oceanic Technol., 18, 1658-1673.

Comstock, J. M., T. P. Ackerman, and G. G. Mace, 2002: Ground-based lidar and radar remote sensing of tropical cirrus clouds at Nauru Island: cloud statistics and radiative impacts. J. Geophys. Res., 107, 10.1029/2002JD002203.

DeSlover, D. H., Smith W. L., Piironen, P. K., and E. W. Eloranta, 1999: A methodology for measuring cirrus cloud visible-to-infrared spectral optical depth ratios. J. Atmos. Oceanic Tech., 16, 251-262.

Donovan, D. P., and A. C. A. P. van Lammeren 2001: Cloud effective particle size and water content profile retrievals using combined lidar and radar observations 1. Theory and examples. J. Geophys. Res., 106, 27,425.

Ebert, E. E., and J. A. Curry, 1992: A parameterization of ice-cloud optical-properties for climate models. J. Geophys. Res., 97, 3831-3836. 
Fu, Q. and K. N. Liou, 1993: Parameterization of the radiative properties of cirrus clouds. J. Atmos. Sci., 50, 2008-2025.

Hartmann, D. L., J. R. Holton, and Q. Fu, 2001: The heat balance of the tropical tropopause, cirrus, and stratospheric dehydration. Geophys. Res. Lett., 28, 19691972.

eymsfield, A. J., and C. M. R. Platt, 1984: A parameterization of the particle size spectrum of ice clouds in terms of the ambient temperature and the ice water content. J. Atmos. Sci., 41, 846-855.

Heymsfield, A. J., A. Bansemer, S. Lewis, J. laquinta, M. Kajikawa, C. Twohey, M. R. Poellot, and L. M. Miloshevich, 2002: A general approach for deriving the properties of cirrus and stratiform ice cloud particles. J. Atmos. Sci., 59, 3-29.

Holton, J. R., and A. Gettelman, 2001: Horizontal transport and the dehydration of the stratosphere. Geophys. Res. Lett., 28, 2799-2802.

Intergovernmental Panel on Climate Change, 2001: Climate Change 2001: The Scientific Basis.

Intrieri, J. M., G. L. Stephens, W. L. Eberhard, and T. Uttal, 1993: A method for determining cirrus cloud particle sizes using a lidar and radar backscatter technique. J. Appl. Meteor., 32, 1074-1082.

Intrieri, J. M., W. L. Eberhard, T. Uttal, J. A. Shaw, J. B. Snider, Y. Han, B. W. Orr, and S. Y. Matrosov, 1995: Multiwavelength observations of a developing cloud system: the FIRE II 26 November 1991 case study. J. Atmos. Sci., 52, 4079-4093. Jazwinsky, A. H., 1970. Stochastic Processes and Filtering Theory, 376 pp., Elsevier, New York. 
Jensen, E. and L. Pfister, 2004: Transport and freeze-drying in the tropical tropopause layer. J. Geophys. Res., 109, doi:10.1029/2003JD004022.

King, M. D., Y. J. Kaufman, W. P. Menzel, and D. Tanre, 1992: Remote sensing of cloud, aerosol, and water vapor properties from the Moderate resolution Imaging Spectrometer (MODIS). IEEE Trans. Geosci. Remote Sens., 30, 2-27.

Korolev, A.., and G. Issac, 2005: Shattering during Sampling by OAPs and HVPS. Part I: Snow Particles. J. Atmos. Oceanic Technol., 22, 528-542.

Lawson, P.R., B.A. Baker, S.G. Schmitt, and T.L. Jensen, 2001: An overview of microphysical properties of Arctic clouds observed in May and July 1998 during FIRE ACE. J. Geophys. Res., 106, 14989-15014.

Liao, L., and K. Sassen, 1994: Investigation of relationships between Ka-band radar reflectivity and ice and liquid water contents. Atmos. Res., 34, 231-248.

Liou, K. N., 1986: Influence of cirrus clouds on weather and climate processes - a global perspective. Mon. Weath. Rev., 114, 1167-1199.

Liu, C. L., and A. J. Illingworth, 2000: Toward more accurate retrievals of ice water content from radar measurements of clouds. J. Appl. Met., 29, 1130-1146.

Mace, G. G., T. P. Ackerman, P. Minnis, and D. F. Young 1998: Cirrus layer microphysical properties derived from surface-based millimeter radar and infrared interferometer data. J. Geophys. Res., 103, 23,207.

Mace, G. G., A. J. Heymsfield, and M. R. Poellot 2002: On retrieving the microphysical properties of cirrus clouds using the moments of the millimeter-wavelength Doppler spectrum. J. Geophys. Res., 107, doi:10.1029/2001JD001308. 
Mace, G.G., S. Benson, and S. Kato, 2006: Cloud radiative forcing at the ARM Climate Research Facility: Part 2. The vertical redistribution of radiant energy by clouds. J. Geophys. Res., in press.

Marshak, A., Y. Knyazikhin, K.D. Evans, W.J. Wiscombe, 2004: The "red versus NIR" plane to retrieve broken-cloud optical depth from ground-based measurements. J. Atmos. Sci., 61, 1911-1925.

Marty, Christoph, R. Philipona, J. Delamere, E. G. Dutton, J. Michalsky, K. Stamnes, R. Storvold, T. Stoffel, S. A. Clough, and E. J. Mlawer, 2003: Downward longwave irradiance uncertainty under arctic atmospheres: Measurements and modeling. J. Geophys. Res., 108, 10.1029/2002JD002937.

Matrosov, S. Y., T. Uttal, J. B. Snider, and R. A. Kropfli, 1992: Estimation of ice cloud parameters from ground-based infrared radiometer and radar measurements. J. Geophys. Res., 97, 11567-11574.

Matrosov, S. Y., 1999: Retrievals of vertical profiles of ice cloud microphysics from radar and IR measurements using tuned regressions between reflectivity and cloud parameters. J. Geophys. Res., 104, 16,741-16753.

Matrosov, S.Y., R.F. Reinking, R.A. Kropfli, B.E. Martner, and B.W. Bartram, 2001: On the use of radar depolarization ratios for estimating shapes of ice hydrometeors in winter clouds. J. Appl. Meteor., 40, 479-490.

Matrosov, S. Y., A. V. Korolev, and A. J. Heymsfield 2002: Profiling cloud ice mass and particle characteristic size from doppler radar measurements. J. Atmos. Ocean. Tech., 19, 1003-1018. 
Matrosov, S. Y., M. D. Shupe, A. J. Heymsfield, P. Zuidema, 2003: Ice cloud optical thickness and extinction estimates from radar measurements. J. Appl. Met., 42 , 1584-1597.

McFarlane, S. A., K. F. Evans, and A. S. Ackerman, 2002: A Bayesian algorithm for the retrieval of liquid water cloud properties from microwave radiometer and millimeter radar data. J. Geophys. Res., 107, 10.1029/2001JD001011.

McFarquhar, G. M. and A. J. Heymsfield. 1996: Microphysical characteristics of three anvils sampled during the Central Equatorial Pacific Experiment. J. Atmos. Sci., 53, $2401-2423$.

Michalsky, J. and coauthors, 2005: Radiative closure studies for clear skies during the ARM 2003 Aerosol Intensive Observational Period, J. Geophys. Res., (in press). Min, Q. and L.C. Harrison, 1996: Cloud properties derived from surface MFRSR measurements and comparison with GOES results at the ARM SGP site. Geophys. Res. Lett., 23, 1641-1644.

Minnis, P., and Coauthors, 1995: Cloud optical property retrieval (Subsystem 4.3). “Clouds and the Earth's Radiant Energy System (CERES) Algorithm Theoretical Basis Document, Volume III: Cloud Analyses and Radiance Inversions (Subsystem 4)", NASA RP 1376 Vol. 3, edited by CERES Science Team, pp. 135-176. innis, P., D. P. Garber, D. Young, R. F Arduini, and Y. Takano, 1998: Parameterizations for reflectance and emittance for satellite remote sensing of cloud properties. J. Atmos. Sci., 55, 3313-3339.

Minnis, P., L. Nguyen, W. L. Smith, Jr., M. M. Khaiyer, R. Palikonda, D. A. Spangenberg, D. R. Doelling, D. Phan, G. D. Nowicki, P. W. Heck, and C. Wolff, 
2004: Real-time cloud, radiation, and aircraft icing parameters from GOES over the USA. Proc. 13th AMS Conf. Satellite Oceanogr. and Meteorol., Norfolk, VA, Sept. 20-24, CD-ROM, P7.1.

Mitchell, D. L., D. H. DeSlover, R. P. d'Entremont, and W. P. Arnott, 2002: Multi-spectral thermal retrievals of ice water path, effective size and photon tunneling. $11^{\text {th }}$ Conference on Atmospheric Radiation, Ogden, UT.

Mitrescu, C., J. M. Haynes, G. L. Stephens, S. D. Miller, G. M. Heymsfield, M. J. McGill, 2005: Cirrus cloud optical, microphysical, and radiative properties observed during the CRYSTAL-FACE experiment: A lidar-radar retrieval system. J. Geophys. Res., 110, 10.1029/2004JD005605.

Noel, V., H. Chepfer, G. Ledanois, A. Delaval, and P.H. Flamant, 2002 : Classification of particle effective shape ratio in cirrus clouds based on lidar depolarization ratio. Appl. Opt., 41, 4245-4257.

Platt, C. M. R. and A. C. Dilley, 1981: Remote sensing of high clouds, Part IV, Observed temperature variations in cirrus optical profiles. J. Atmos. Sci., 38, 1069-1082.

Randall, D. and coauthors, 2003: Confronting models with data - The GEWEX cloud systems study. Bull. Amer. Met. Soc., 84, 455-469.

Rodgers, C. D., 2000. Inverse Methods for Atmospheric Sounding: Theory and Practice, 238 pp., World Sci., Boca Raton, Fla.

Rosenfield, D. E., D. B. Considine, M. R. Schoeberl, and E. V. Browell, 1998: The impact of subvisible cirrus clouds near the tropical tropopause on stratospheric water vapor. Geophys. Res. Lett., 25, 1883-1886. 
Sassen, K., 1987: Ice cloud content from radar reflectivity. J. Climate Appl. Meteor., 26, 1050-1053.

Sassen, K., and J.M. Comstock, 2001: A Midlatitude Cirrus Cloud Climatology from the Facility for Atmospheric Remote Sensing. Part III: Radiative Properties. J. Atmos. Sci., 58, 2113-2127.

Sassen, K., Z. Wang, V. I. Khvorostyanov, G. L. Stephens, and A. Benedetti, 2002: Cirrus cloud ice water content radar algorithm evaluation using an explicit cloud microphysical model. J. Appl. Meteor., 41, 620-628.

Sherwood, S. C., 1999: On moistening of the tropical troposphere by cirrus clouds. J. Geophys. Res., 104, 11949-11960.

Stephens, G. L., R. J. Engelen, M. Vaughan, and T. L. Anderson, 2001: Toward retrieving properties of the tenuous atmosphere using space-based lidar measurements. J. Geophys. Res., 106, 28143-28157.

Turner, D.D., D.C. Tobin, S.A. Clough, P.D. Brown, R.G. Ellingson, E.J. Mlawer, R.O. Knuteson, H.E. Revercomb, T.R. Shippert, and W.L. Smith, 2004: The QME AERI LBLRTM: A closure experiment for downwelling high spectral resolution infrared radiance. J. Atmos. Sci., 61, 2657-2675.

Turner, D. D., 2005: Arctic mixed-phase cloud properties from AERI-lidar observations: Algorithm and results from SHEBA. J. Appl. Meteor., 44, 427-444.

Twohy, C.H., A.J. Schanot and W.A. Cooper, 1997: Measurement of condensed water content in liquid and ice clouds using an airborne counterflow virtual impactor. J. Atmos. Oceanic Tech., 14, 197-202. 
Wang, Z., and K. Sassen, 2002: Cirrus cloud microphysical property retrieval using lidar and radar measurements. Part I: Algorithm description and comparison with in situ data. J. Appl. Met., 41, 218.

Wielicki, B. A., B. R. Barkstrom, E. F. Harrison, B. B. Lee III, G. L. Smith, and J. E. Cooper, 1996: Clouds and the Earth's Radiant Energy System (CERES): An Earth Observing System experiment. Bull. Amer. Meteor. Soc., 77, 853-868.

Wylie, D. P., and W. P. Menzel, 1999: Eight years of high cloud statistics using HIRS. J. Climate, 12, 170-184. 
Figure Captions

Fig. 1. Images obtained by the Whole Sky Imager (left column) on 9 March 2000 at (a) 1926, (b) 2032, (c) 2102, (d) 2130, and (e) 2214 UTC. Also shown are images obtained by the Cloud Particle Imager during in situ flights aboard the University of North Dakota Citation aircraft.

Fig. 2. Time vs. height display of (a) MMCR reflectivity in $\mathrm{dBz}$ and (b) MPL normalized backscatter observed on 9 March 2000.

Fig. 3. Time series of visible optical depth on 9 March 2000 retrieved by (a) lidar-radar and reflectivity-Doppler velocity algorithms, (b) empirical, lidar only, and reflectivity-IR algorithms, and (c) spectral infrared algorithms. The "AVG" line represents the average $\tau_{v}$ for all algorithms included in the intercomparison. Note that MAT-EMP is the only empirical algorithm that produces $\tau_{v}$ and that the RAMAN and COM-Lidar algorithms retrieve only $\tau_{v}$ and therefore are not included in the IWP comparisons (Fig. 4).

Fig. 4. Time series of IWP on 9 March 2000 retrieved by (a) lidar-radar and reflectivityDoppler velocity, (b) empirical and reflectivity-IR, and (c) spectral infrared algorithms. The "AVG" line represents the average IWP for all algorithms included in the intercomparison.

Fig. 5. Comparison of ground based, in situ (CVI) and satellite measurements (VISST) of (a) IWP and (b) visible optical depth on 9 March 2000. The vertical bars associated with the CVI IWP represents the standard deviation of the mean IWP over a 2 min interval as the aircraft passed over the SGP CRF. The "AVG" line represents the average of all ground based values, and the shaded region represents the $\mathrm{min} / \mathrm{max}$ spread in $\tau_{v}$ or IWP at that time.

Fig. 6. Comparison of modeled and measured downwelling shortwave flux at the surface on 9 March 2000. The model "avg", "min", and "max' $\tau$ represent the model flux using average, minimum, and maximum visible optical depth as inputs into the radiative transfer model. The observed flux is from a hemispherical pyranometer located at the SGP CRF. Note that the periods when the observed flux is greater than the model clear sky demonstrates how 3D effects can enhance the downward flux due to horizontal inhomogeneities in the cloud when the optical depth is relatively small $\left(\tau_{v}<1.0\right)$.

Fig. 7. Comparison of model and AERI measured radiance on 9 March 2000 at $\sim 3.8 \mu \mathrm{m}$ for (a) algorithms the do not use IR measurements and (b) for algorithms that use IR measurements. Note that we do not include MD-AERI results because their algorithm uses the $3 \mu \mathrm{m}$ band to retrieve the cloud microphysical properties. 
Table 1. Algorithms included in the high clouds retrieval intercomparison.

\begin{tabular}{|c|c|c|c|}
\hline & Short-Name & Retrieval Type & Reference/Participant \\
\hline \multirow{8}{*}{ 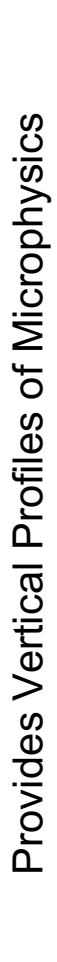 } & DV-LR-ros & $\begin{array}{l}\text { Lidar-Radar assuming } \\
\text { bullet rosette crystals }\end{array}$ & $\begin{array}{l}\text { Donovan and van Lammeren } \\
\text { (2001) /McFarlane }\end{array}$ \\
\hline & DV-LR-col & $\begin{array}{l}\text { Lidar-Radar assuming } \\
\text { hexagonal column crystals }\end{array}$ & $\begin{array}{l}\text { Donovan and van Lammeren } \\
\text { (2001) /McFarlane }\end{array}$ \\
\hline & ZW-LR & Lidar-Radar & Wang and Sassen (2002)/Wang \\
\hline & MAT-ZV & $\begin{array}{l}\text { Radar Reflectivity-Doppler } \\
\text { Velocity }\end{array}$ & Matrosov et al. (2002)/Matrosov \\
\hline & MACE-ZV & $\begin{array}{l}\text { Radar Reflectivity-Doppler } \\
\text { Velocity }\end{array}$ & Mace et al. (2002)/Mace \\
\hline & MAT-EMP & Empirical & Matrosov et al. (2003)/Matrosov \\
\hline & KS-EMP & Empirical & Sassen 1987 / Sassen \\
\hline & ILL-EMP & Empirical & $\begin{array}{l}\text { Liu and Illingworth } \\
\text { (2000)/Comstock }\end{array}$ \\
\hline \multirow{8}{*}{ 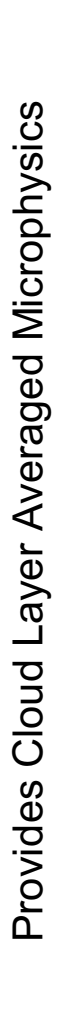 } & RAMAN & Lidar only & Beer's Law/Comstock \\
\hline & COM-Lidar & Lidar only & $\begin{array}{l}\text { Comstock and Sassen } \\
\text { (2001)/Comstock }\end{array}$ \\
\hline & MAT-ZIR & $\begin{array}{l}\text { Radar Reflectivity-IR } \\
\text { radiance }\end{array}$ & Matrosov et al. (1999)/Matrosov \\
\hline & MACE-ZIR & $\begin{array}{l}\text { Radar Reflectivity-IR } \\
\text { radiance }\end{array}$ & Mace et al. (1998)/Mace \\
\hline & $\begin{array}{l}\text { DT-AERI- } \\
\text { hex }\end{array}$ & $\begin{array}{l}\text { Spectral IR assuming } \\
\text { hexagonal column crystals }\end{array}$ & Turner (2005)/Turner \\
\hline & $\begin{array}{l}\text { DT-AERI- } \\
\text { sph }\end{array}$ & $\begin{array}{l}\text { Spectral IR assuming } \\
\text { spheres }\end{array}$ & Turner (2005)/Turner \\
\hline & DES-AERI & Spectral IR & DeSlover et al. (1999)/DeSlover \\
\hline & MD-AERI & Spectral IR & $\begin{array}{l}\text { Mitchell et al. (2002)/Mitchell \& } \\
\text { d'Entremont }\end{array}$ \\
\hline
\end{tabular}




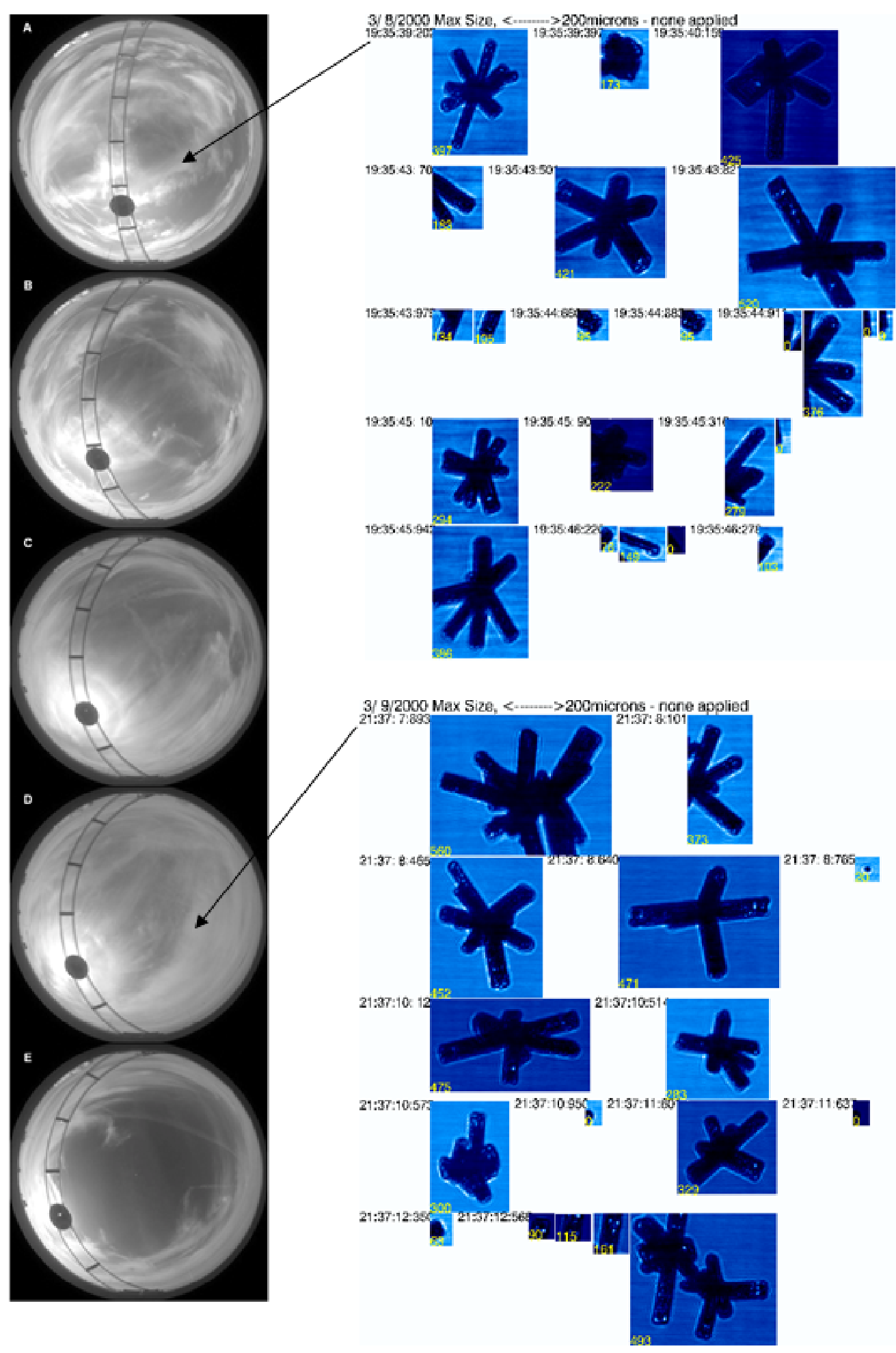

Fig. 1. Images obtained by the Whole Sky Imager (left column) on 9 March 2000 at (a) 1926, (b) 2032, (c) 2102, (d) 2130, and (e) 2214 UTC. Also shown are images obtained by the Cloud Particle Imager during in situ flights aboard the University of North Dakota Citation aircraft. 

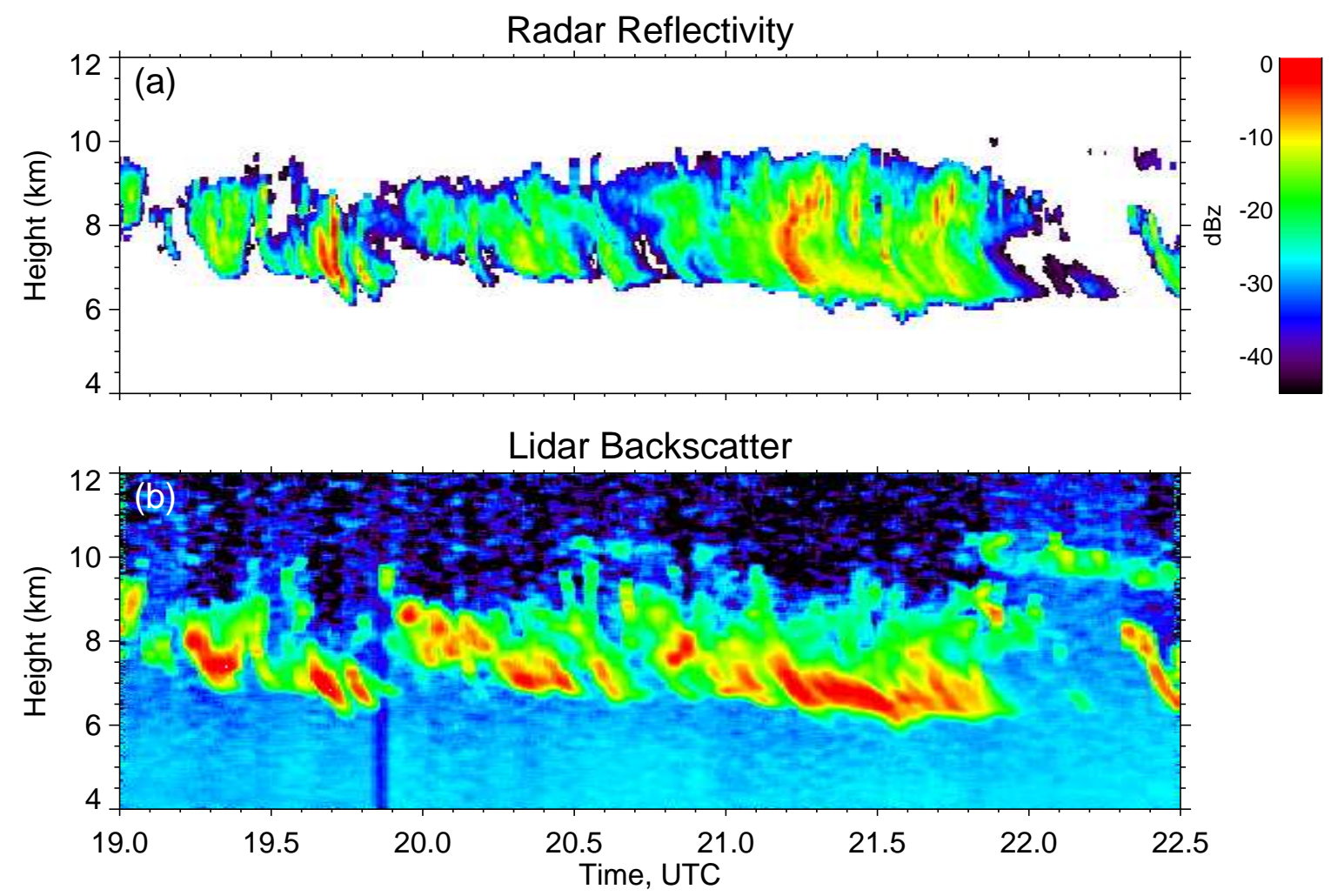

Fig. 2. Time vs. height display of (a) MMCR reflectivity in $\mathrm{dBz}$ and (b) MPL normalized backscatter observed on 9 March 2000. 

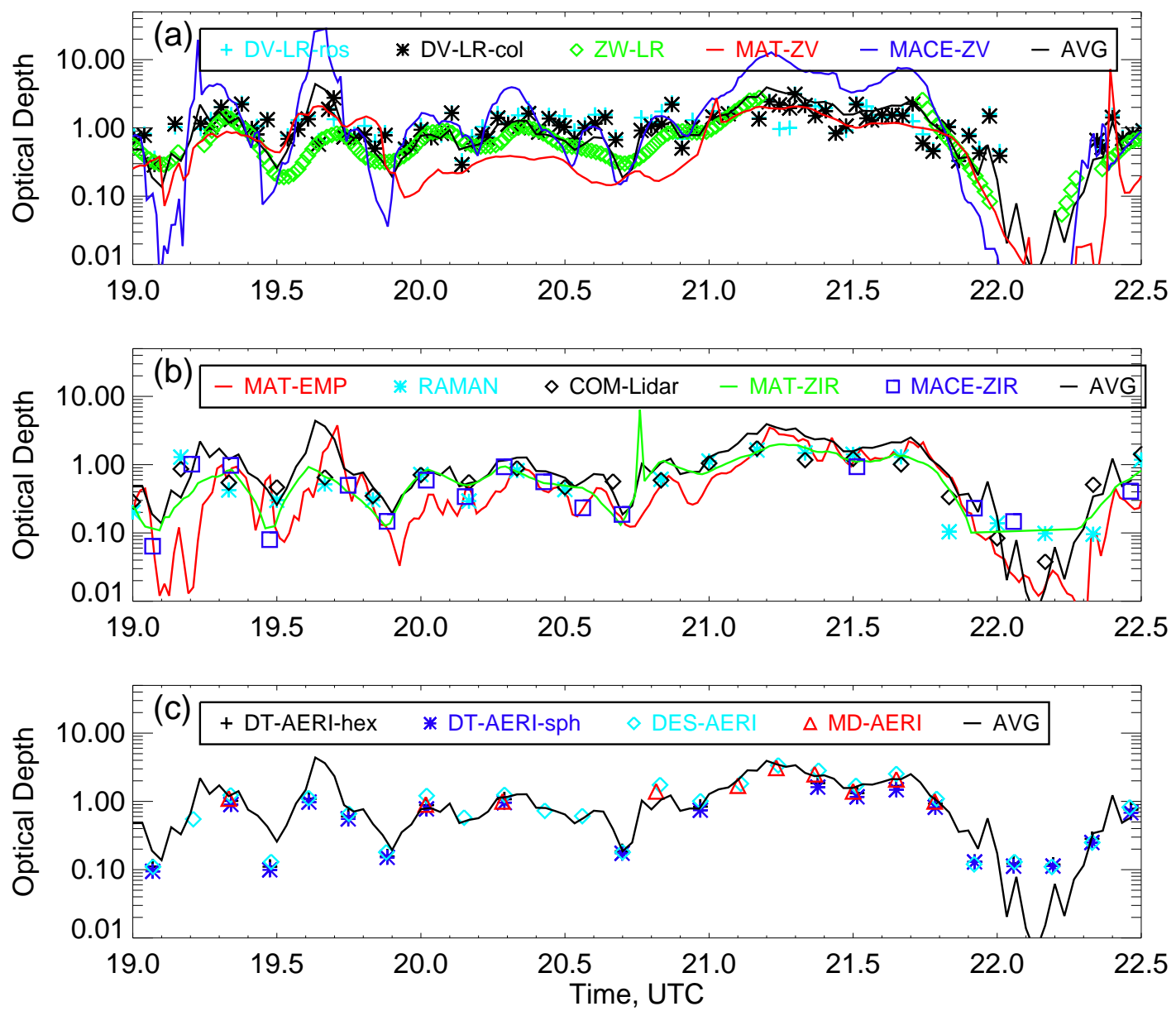

Fig. 3. Time series of visible optical depth on 9 March 2000 retrieved by (a) lidar-radar and reflectivity-Doppler velocity algorithms, (b) empirical, lidar only, and reflectivity-IR algorithms, and (c) spectral infrared algorithms. The "AVG" line represents the average $\tau_{v}$ for all algorithms included in the intercomparison. Note that MAT-EMP is the only empirical algorithm that produces $\tau_{v}$ and that the RAMAN and COM-Lidar algorithms retrieve only $\tau_{v}$ and therefore are not included in the IWP comparisons (Fig. 4). 

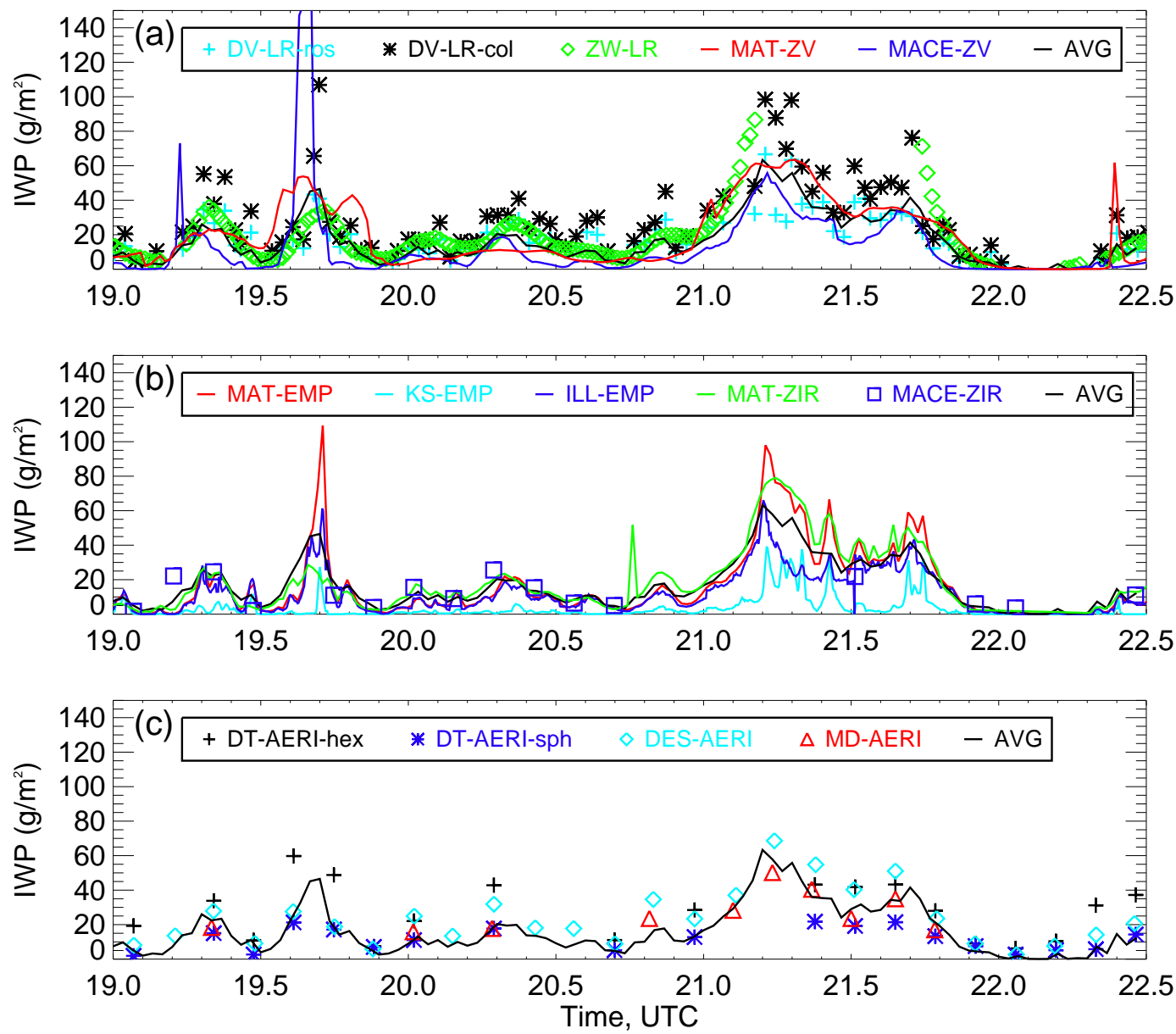

Fig. 4. Time series of IWP on 9 March 2000 retrieved by (a) lidar-radar and reflectivityDoppler velocity, (b) empirical and reflectivity-IR, and (c) spectral infrared algorithms. The "AVG" line represents the average IWP for all algorithms included in the intercomparison. 

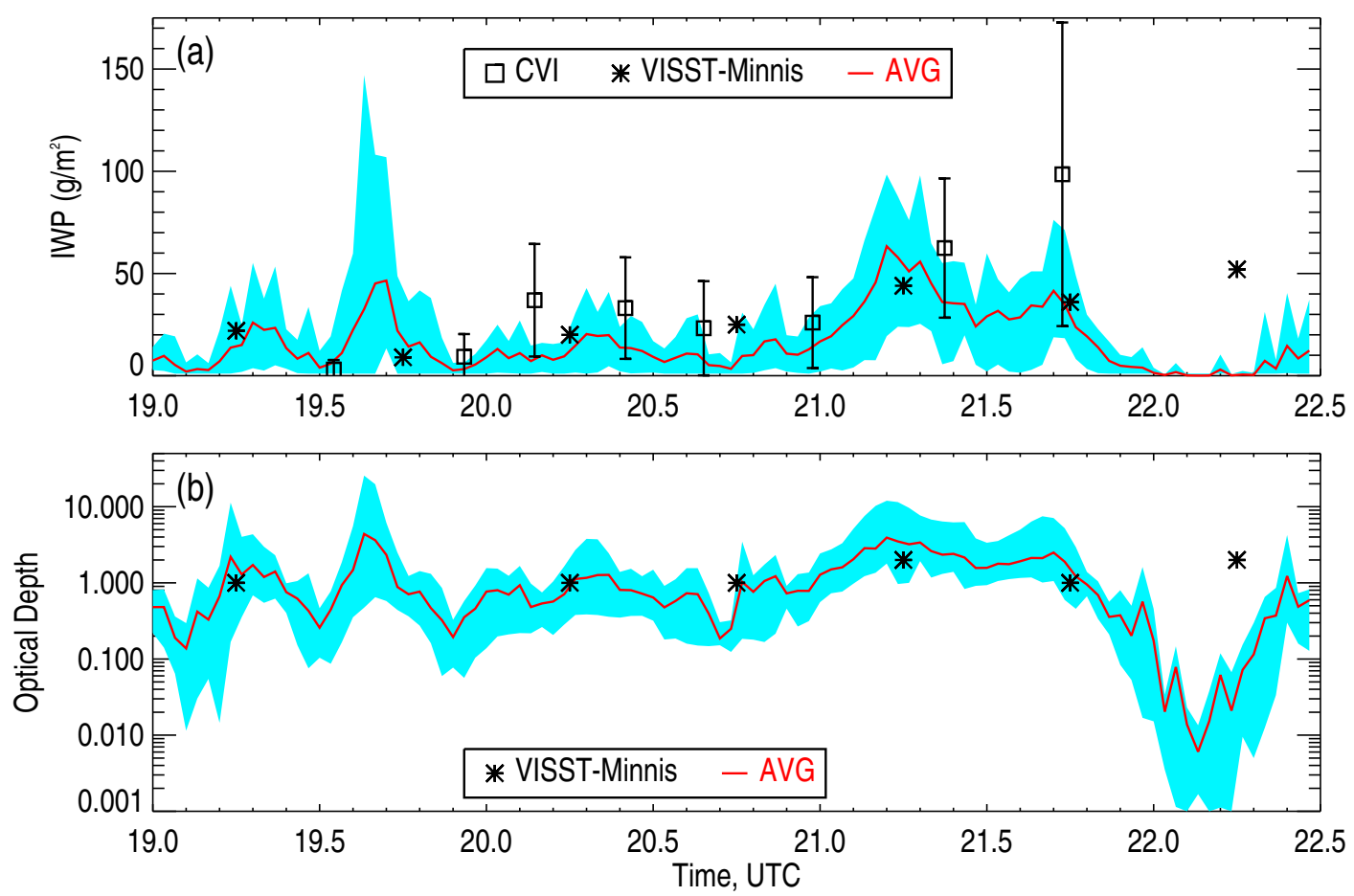

Fig. 5. Comparison of ground based, in situ (CVI) and satellite measurements (VISST) of (a) IWP and (b) visible optical depth on 9 March 2000. The vertical bars associated with the CVI IWP represents the standard deviation of the mean IWP over a 2 min interval as the aircraft passed over the SGP CRF. The "AVG" line represents the average of all ground based values, and the shaded region represents the $\mathrm{min} / \mathrm{max}$ spread in $\tau_{v}$ or IWP at that time. 


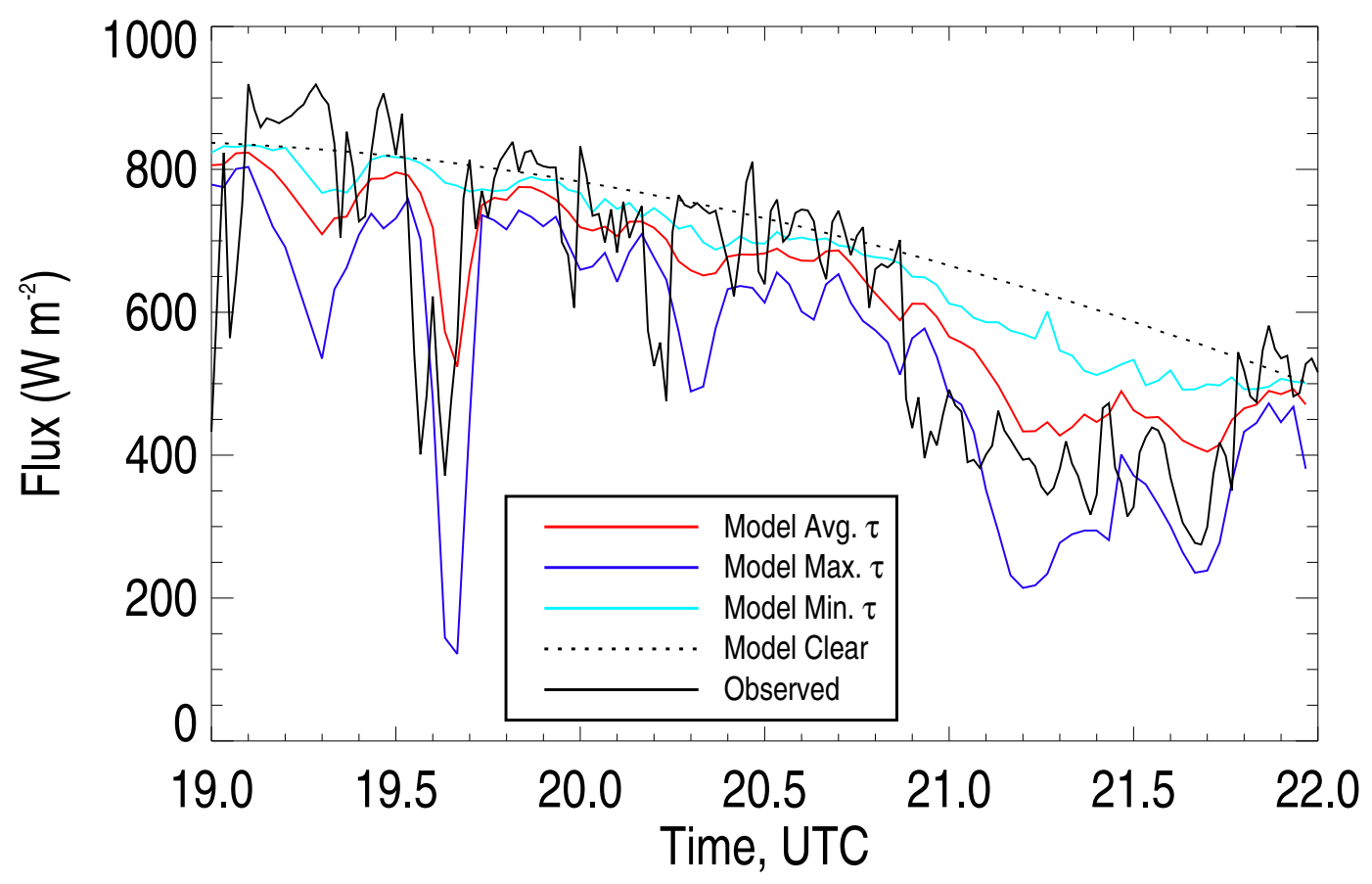

Fig. 6. Comparison of modeled and measured downwelling shortwave flux at the surface on 9 March 2000. The model "avg", "min", and "max' $\tau$ represent the model flux using average, minimum, and maximum visible optical depth as inputs into the radiative transfer model. The observed flux is from a hemispherical pyranometer located at the SGP CRF. Note that the periods when the observed flux is greater than the model clear sky demonstrates how 3D effects can enhance the downward flux due to horizontal inhomogeneities in the cloud when the optical depth is relatively small $\left(\tau_{v}<1.0\right)$. 

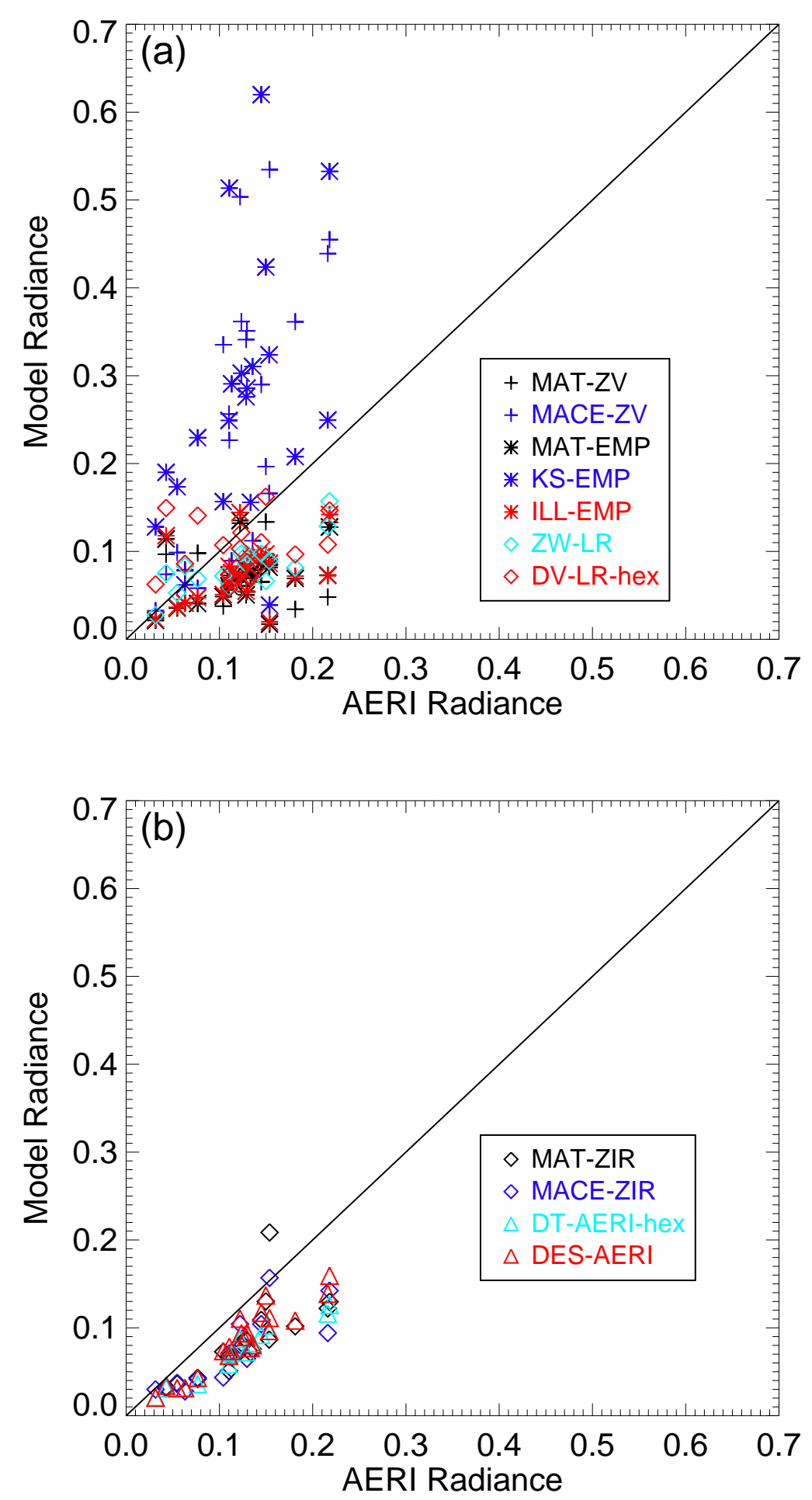

Fig. 7. Comparison of model and AERI measured radiance on 9 March 2000 at $\sim 3.8 \mu \mathrm{m}$ for (a) algorithms the do not use IR measurements and (b) for algorithms that use IR measurements. Note that we do not include MD-AERI results because their algorithm uses the $3 \mu \mathrm{m}$ band to retrieve the cloud microphysical properties. 